\title{
MAPPING EXTENSION AND MAGNITUDE OF CHANGES INDUCED BY CYCLONE IDAI WITH MULTI-TEMPORAL LANDSAT AND SAR IMAGES
}

\author{
C. Amisse*, M. E. Jijon-Palma, J. A. S. Centeno \\ ${ }^{1}$ UFPR, Federal University of Paraná, Centro Politécnico, 81530-000 Curitiba/PR, Brazil - (caamisse, majijpa) @gmail.com \\ centeno@ufpr.br
}

KEY WORDS: Change Detection, Landsat, SAR, Cyclone IDAI, Mozambique

\begin{abstract}
:
In this paper it is described a study case of a rapid assessment of change detections for post-cyclone Idai vegetated damage and flood extension estimation by fusion of multi-temporal Landsat and sentinel-1 SAR images. For automated change detection, after disasters, many algorithms have been proposed. To visualize the changes induced by cyclone we tested and compared two automated change detection techniques namely: Principal Components Analysis (PCA), Normalized Difference Vegetation Index (NDVI) and image segmentation. With the image segmentation of multispectral and SAR images, it was possible to visualize the extension of the wet area. For this specific application, PCA was identified as the optimal change detection indicator than NDVI. This study suggested that image segmentation, principal components analysis, and normalized difference vegetation index can be used for change detection of surface water due to flood and disasters especially in prone countries like Mozambique.
\end{abstract}

\section{INTRODUCTION}

The landfall of cyclone IDAI in southwest Africa during 14th March to 16th March 2019, considered one of the worst disasters of the last 20 years, has resulted in the destruction of communities in Mozambique, Malawi, and Zimbabwe, with greater severity in the province of Sofala (Mozambique), particularly in the city of Beira and the suburban spots of Dondo and Búzi villages. The category 4 tropical cyclone IDAI caused the death of citizens and animals, destroyed infrastructure, as well as the different typical land-cover classes of that region. After such events, one of the post-catastrophe needs is to identify and quantify losses as well as changes in a different landscape, land cover, and infrastructures, seeking to plan and coordinate the damage restoration. This task involves the analysis of a huge area and becomes more difficult in less developed countries, because of the limited financial resources. Therefore, remote sensing is a very valuable tool to help solve such problems. Satellite imagery allows inspecting the affected area, providing useful information for the previously mentioned needs. The information contained in remote sensing images can be analyzed and the changes quantified. This task is carried out using at least two images covering the same geographic area, necessarily being one before and another after the catastrophe. The result of the analysis of the two images (pre- and postcatastrophe) is presented as a thematic image, known as a change detection map. The change detection map contains two "groups" of pixels, one representing changes and the second without changes. Change detection is a well-studied topic in remote sensing and a wide range of methods have been developed, tested and applied. Such methods range from visual comparison to detailed quantitative approaches (Wickware and Howarth, 1981). Some of these methods, their specificities, advantages, and disadvantages are summarized in $\mathrm{Lu}$, et al., 2004 and Hussain, et al., 2013.

By using well-established change detection techniques in the literature, this paper aims at detecting the changes that occurred in Beira (study region) after landfall of cyclone IDAI. Concretely, visualize the destruction of built-up areas, vegetation and the extent of flooded areas. To do this, it is used two remote sensing data sources: Landsat 8 OLI/TIRS (Operational Land Imager/Thermal Infrared Sensor) multitemporal dataset and Sentinel-1 synthetic aperture radar
(SAR) and two techniques, namely Principal Component Analysis and Normalized Difference Vegetation Index, are used to perform change detection.

The PCA method is based on the Principal Components Transform, which allows enhancing the spectral differences between materials or surfaces. In PCA, the set of correlated variables (original bands) is transformed into uncorrelated variables (main components) that contain the information with a physical meaning that needs to be explored. According to Jensen (1986), PCA is one of the best techniques for detecting changes in remote sensing.

When applied to pre- and post-catastrophe images, there are two options to use the principal components to detect changes. Given two or more images, the principal components can be computed from each date's image separately and the obtained PCA images compared. For example, the differences can be estimated computing the difference between the principal component of the first and second dates. In the stacked approach, all available bands of the two dates are stored as a unique data set and the variance-covariance matrix is computed from this stacked image. This allow computing the principal components of the whole set. The first principal component will provide information about unchanged areas, while the second one will contain all changed information. Areas of "major" change are found in the histogram tails of the image.

Another valid option to evaluate vegetation cover changes that was used in this study is to compare vegetation indexes before and after the event. NDVI is described by Rouse et al. (1973) as the ratio between the difference of the measurement of the reflectance in the near-infrared and red bands and the sum of these channels, given by equation 1 .

$$
N D V I=\frac{\sigma N I R-\sigma R E D}{\sigma N I R+\sigma R E D}
$$

Where NIR is the reflectance on the Near Infrared (5th) band, and RED is the red (4th) band of the Landsat 8 scene sensor bands. The NDVI value can range from -1 to +1 .

\section{STUDY SITE AND DATASET}

The study area is located at Sofala bay, on the eastern coast of the African continent (Figure 1). Beira is a coastal city, 
characterized by a low-level topography. Located in an estuarine environment, in a marshy region, closer to the estuary of the Púngué and Búzí rivers (Nzualo and Rosman, 2010), and on coastal dune alignments (Consultec, 2007). The study area is bounded between parallels $19^{\circ} 30^{\prime}$ to $19^{\circ} 52^{\prime} \mathrm{S}$ and meridians $34^{\circ} 30^{\prime}$ to $35^{\circ} 10^{\prime} \mathrm{W}$. The study area includes the suburban spots of Dondo and Búzi villages.

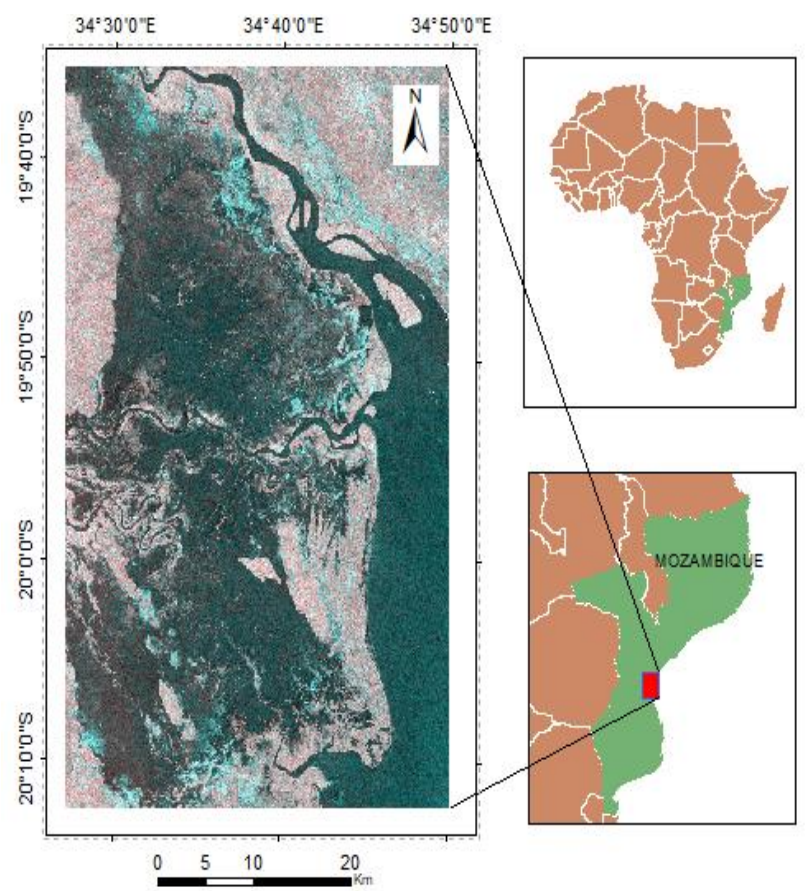

Figure 1: Study area

During 14th March to 16th March 2019 Cyclone Idai lashed Beira with winds of up to $194 \mathrm{~km} / \mathrm{h}$, before moving inland to Zimbabwe and Malawi, flattening buildings and threatening millions of lives. It is estimated that at least 600,000 people have been affected, in this event. A subset of a SAR image recorded by Sentinel 1 on March 14, 2019 at 16:06:46 GMT is shown in Fig. 2 approaching the inland.

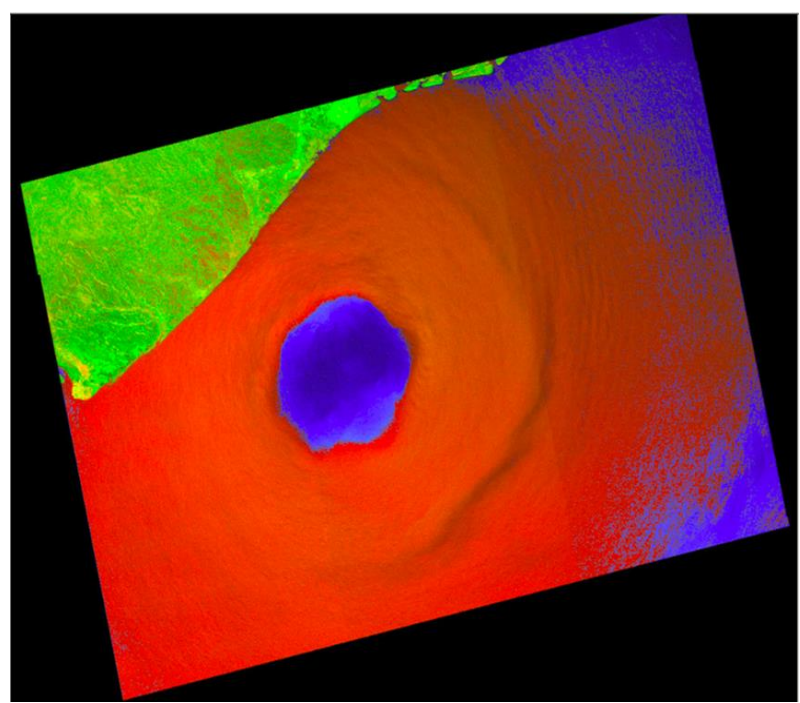

Figure 2. Eye of Cyclone Idai approaches the Coast of Mozambique (image of Sentinel - 1, Path/ Frame: 101/1113).
To map the flood extension and land-cover change for the study area, pre and post-event multi-spectral Landsat 8 OLI/TIRS images covering Beira were collected from the USGS website (http://earthexplorer.usgs.gov/). The pre-event image was acquired on November 6, 2018, and the post-event image was acquired on October 24, 2019, and all of them were cloud-free. Images of the event's date and subsequent days had clouds.

To visualize the flooded area it was used Sentinel-1 data obtained from https://www.asf.alaska.edu. The sensor radar data set in SLC (Single Look Complex) form were acquired on March 14, 2019. Sentinel-1 SAR operates at C-band, in a wavelength of $5.6 \mathrm{~cm}$, and the interferometric wide swath (IW) operated in the default mode, which acquires the image in a dual-polarized manner with VV/VH polarization. Sentinel-1 SAR consists of two satellites, Sentinel-1A and Sentinel-1B in the same orbit. Sentinel-1 products are more applicable to flooding mapping because of its high revisit frequency, which is only 12 days for each satellite, 6 days for the combined constellation, The product delivery is also considered rapid, which makes it a good resource for flood monitoring. The microwave $\mathrm{C}$-band radiation is able to penetrate clouds and work regardless of weather conditions during day and night. Pre-event and SAR images were geometrically co-registered and, in the process, the multispectral images were resampled to $15 \mathrm{~m}$ using nearest neighbour resampling.

\section{METHODOLOGY}

Among many change detection techniques, in this research the techniques evaluated are Principal Component Analysis (PCA) and Vegetation Index comparison. The main steps of the methodology are shown in figure 3 .

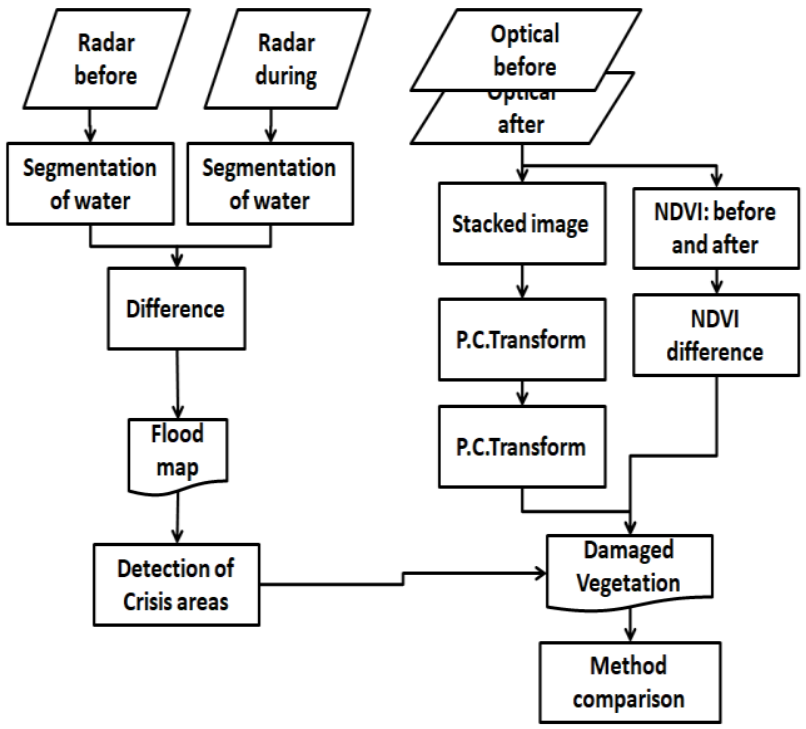

Figure 3: Schematic diagram used in the study.

In the pre-processing step, all available images were registered using the 2018 Landsat image as reference.

First, the radar image during the cyclone was analyzed to identify flooded areas. This enables a holistic view of the affected regions and municipalities. Two images, one before and other during the cyclone were binarized considering two 
classes: "water" (1) and "others" (0). Then, they were compared, according to table 1

Table 1 - classification of the binary images obtained from the radar data: dif $=$ radar (during cyclone) - radar (before cyclone)

\begin{tabular}{cccc}
\hline & \multicolumn{2}{c}{ during } & \\
& & Water & Background \\
\hline before & Water & Water - permanent & - \\
& Background & Flooded & No flooded \\
\hline
\end{tabular}

With this result, the study was focused on three more affected areas: city of Beira and the suburban spots of Dondo and Búzi villages. It is important to quote that this is only possible with radar images because cloud cover is very high during a cyclone, which makes it impossible to obtain optical images of the earth's surface. To delimitate the extent of flood, we compute the mask map from multitemporal and radar registered image.

\subsection{Detailed analysis}

In the next steps, the Landsat images obtained before and after the cyclone were analyzed using two approaches: the vegetation index and PCA.

The vegetation index of each date image (November 6, 2018 and October 24, 2019) was computed for comparison purposes. Each NDVI image stores values that range from -1 to 1 and these values can be segmented in clusters with similar NDVI values. In a first step, the images were segmented (using a threshold) into two classes, vegetation, and non-vegetation. The result is a binary image, where 1 corresponds to the objects (vegetation) and 0 to the background (others). With two binary images, one obtained before and the other after the disaster it is possible to quantify vegetation changes by arithmetic operations. The necessary thresholds were obtained using the OTSU method, a method that maximizes the difference between the possible two classes (Otsu, 1979).

A second analysis was performed computing the principal components of a stacked image. For this purpose, the two Landsat images (before and after) were stacked in a single multitemporal image. All 6 bands (i.e. green, red and near infrared bands of each image date) of the pre-disaster and postdisaster images were stacked to obtain a single image. Then, then principal component transform was applied to this new composite, which enabled computing the principal components of the multitemporal data set. Finally, the resulting Principal Components were analyzed to detect changes in the areas of the city of Beira, Dondo and Búzi villages.

Finally, the results are compared and the advantages of both methods, for this problem in the specific area, analyzed. The advantages and disadvantages of each method also allow the proposal of a combined approach that uses the best characteristics of each solution.

\section{EXPERIMENTS AND ANALYSIS}

In the first part of the study, a more holistic analysis was performed using radar images and aiming at detecting flooded areas. Figure 4 shows the result of this step. In the image, changes three classes are displayed, permanent water (unchanged, like ocean and rivers) and in the study area and flooded areas are marked light. Small water bodies were not detected due to the spatial resolution of the radar image.

Based on the segmentation image, during the period of pre to post disaster, flooded area class, water body, non flooded area, vegetation and anthropic were measured as shown in Table 2 and Table 3.

Table 2 and Table 3 shows area decreases in non flooded area and increases in the other land covers in the image. For all land covers, the difference is around $17.19 \%$. It is consistent with the assumption that short plant was submerged by the flooding, which causes increase of wet area and decrease of green area around city of Beira, Búzi and Dondo villages.

Table 2. Representation in values of the study area

\begin{tabular}{lcc}
\hline \multicolumn{1}{c}{ Item } & Area $\left(\mathrm{km}^{2}\right)$ & Percentage $(\%)$ \\
\hline total area & 2720.00 & 100.00 \\
vegetation and anthropic & 2252.35 & 82.81 \\
water body & 467.65 & 17.19 \\
\hline
\end{tabular}

Table 3. Representation in values flooded and non-flooded areas

\begin{tabular}{lcc}
\hline \multicolumn{1}{c}{ Item } & Area $\left(\mathrm{km}^{2}\right)$ & Percentage $(\%)$ \\
\hline vegetation and anthropic & 2252.35 & 100.00 \\
flooded area & 1594.17 & 70.78 \\
non flooded area & 658.19 & 29.22 \\
\hline
\end{tabular}

It is noticeable that the damages were concentrated around the city of Beira, Búzi and Dondo villages. That is the reason why the remaining study was devoted to these specific regions. In figure 5,6 and $7, \mathrm{a}$ and $\mathrm{b}$, parts of the Landsat images of these regions, before and after the cyclone, are displayed. Visually, it is possible to notice some changes, such as the reduction $\mathrm{f}$ green areas in the images after the event. A general increase of the brightness is also noticeable and it can be explained because the amount of soil in the pixel increased because of the removal of vegetation. Due to the flood followed by rainfall and strong winds, the post-disaster images show a decrease in the vegetated surface, built-up area, and variation of humid area.

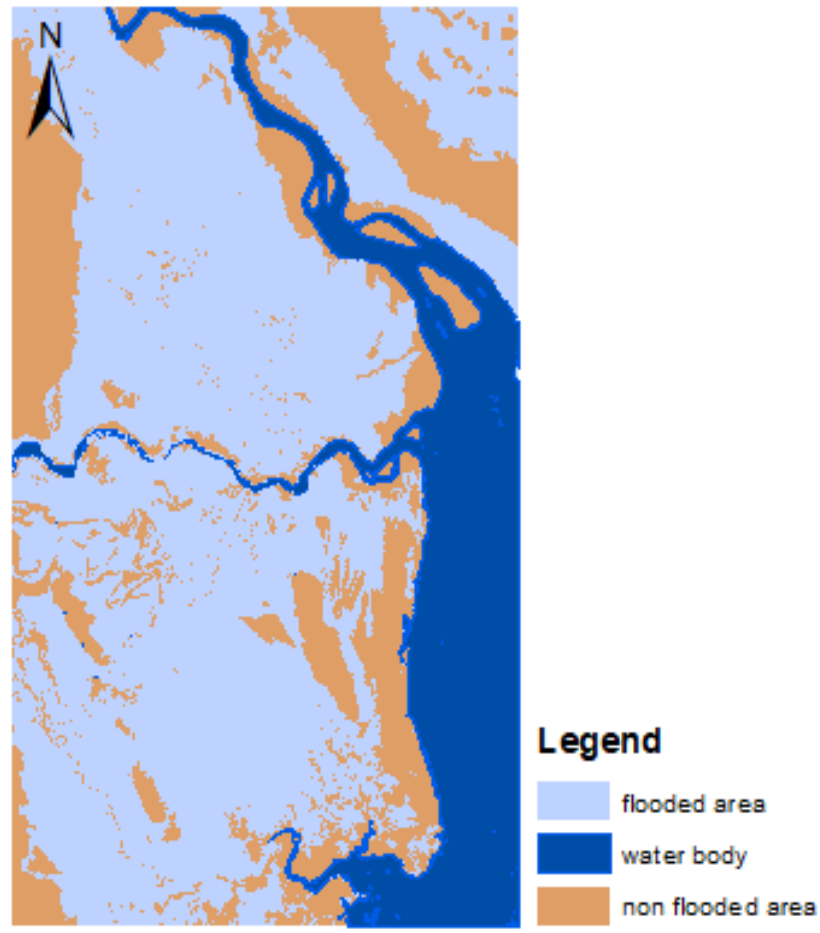

Figure 4. Classification results of multi-spectral and SAR images. 


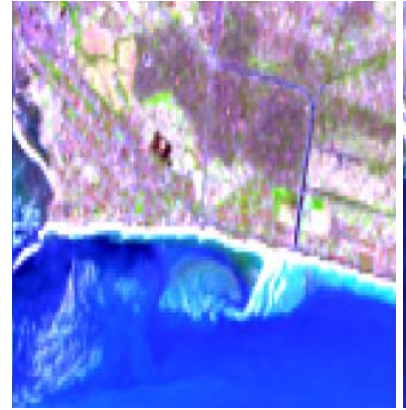

[a]

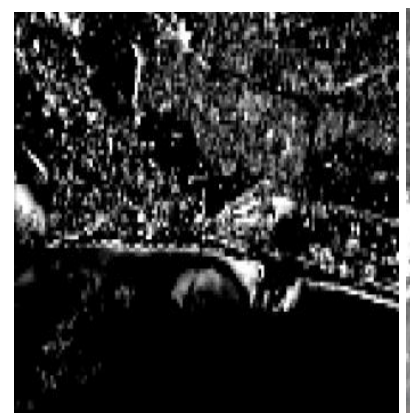

[c]

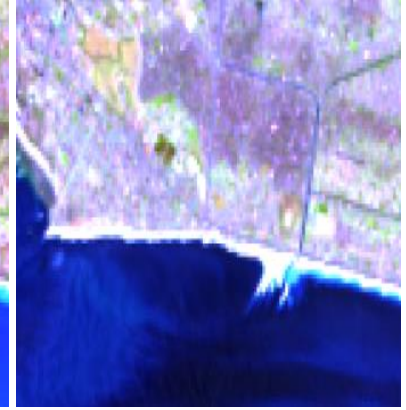

[b]

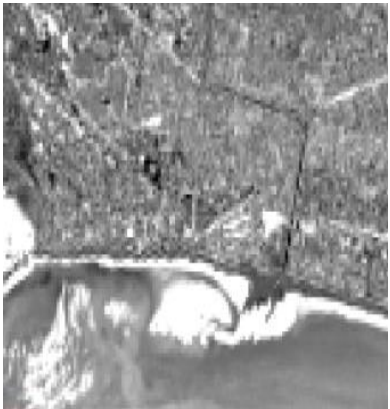

[d]

Figure 5: Subset of the Beira city [a] before, [b] after destruction, and change detection results for [c] $\mathrm{PC}$ and [d] NDVI methods.

In the lower part of these figures (c and d) the result of the two approaches is displayed: result of the PCA (c) and NDVI (d). The visual interpretation of PCA and NDVI images, suggests that the bright regions represent vegetation which has been cleared in Beira city, Búzi and Dondo villages. This is for example visible in the central portion of image 5a, the Palmeiras district of Beira, where very bright areas are displayed in figures $5 \mathrm{c}$ and $5 \mathrm{~d}$. The reduction of vegetation is less intense in the northern portion of the district, close to the main road visible as a dark curve figure $5 \mathrm{~d}$ and better visible in figure 8 . This can be explained because this region is covered by smaller houses without urban vegetation on the streets. On the other hand, some bright areas in the unordered northern settlement of this district show that something changed. As the NDVI shows that there were not detected vegetation changes, then it can be assumed that these changes are caused by other phenomena, like the destruction of buildings.

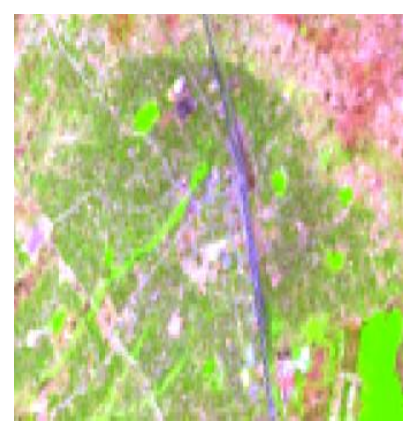

[a]

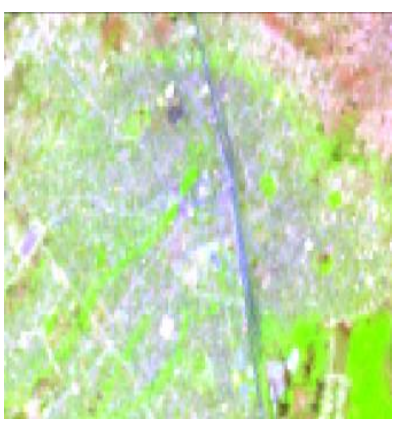

[b]

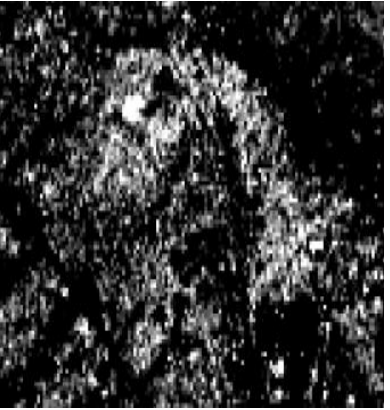

[c]

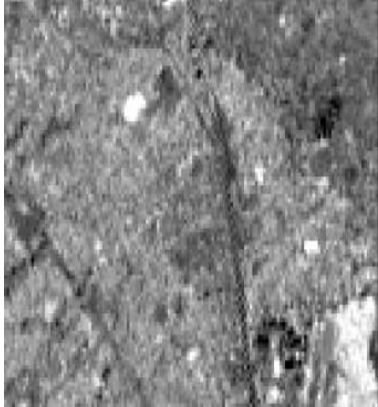

[d]
Figure 6: Subset of the Dondo village city [a] before, [b] after destruction, and change detection results for [c] PC and [d] NDVI methods.

A Comparison of the results shows some coincidences and the advantages of the methods. Both methods enable detecting the loss of vegetation from the surface.

The intensity of the damages seems more intense around Dondo village. Here, both results, PCA and NDVI show a great protion of bright areas in figure 6 . As it is visible in figure $8 \mathrm{~b}$, this region has a dense vegetation coverage, which was damaged during the cyclone.

Finally, the results obtained analyzing the images around Búzi (Figure 7) show the same tendency as the one verified in Dondo. The cyclone affected the vegetation cover with high intensity and reduced the green coverage of the area. So, more soil is visible in the pixels. These changes are visible in the vegetation index and also in the PCA transform results. Generally, PCA performs well and visually enhances changes while the NDVI index underestimated changes and produces many false alarms.

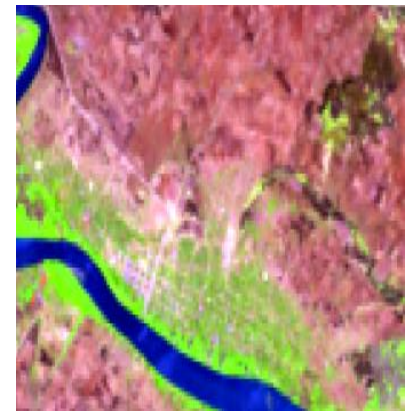

[a]

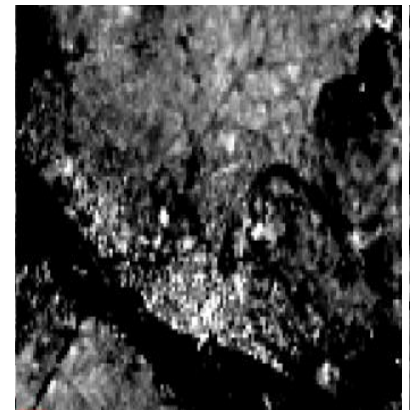

[c]

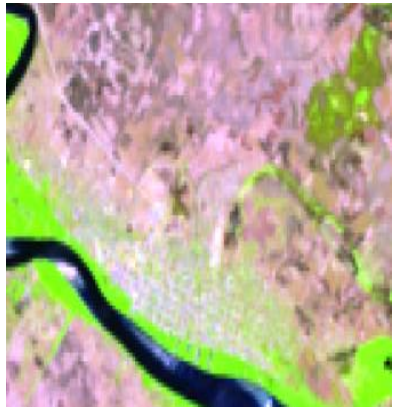

[b]

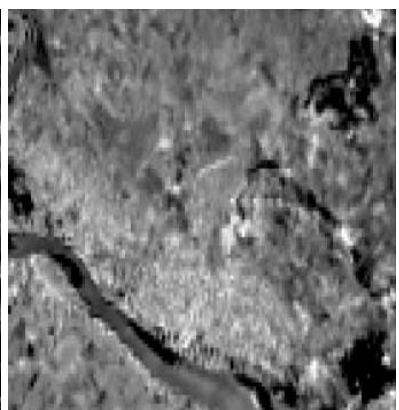

[d]
Figure 7: Subset of the Búzi village city [a] before, $[\mathrm{b}]$ after destruction, and change detection results for [c] PC and [d] NDVI methods. 


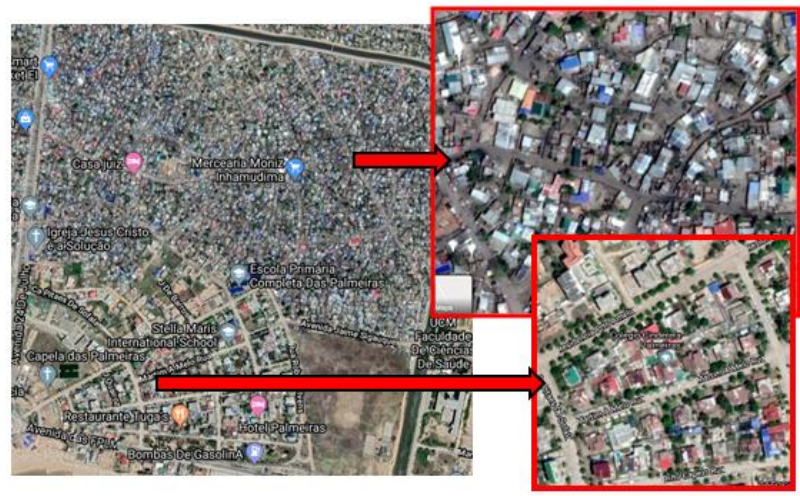

(a)

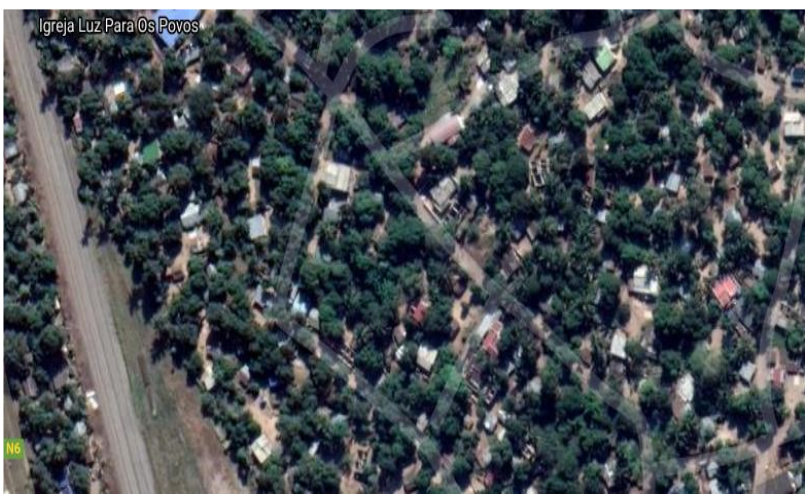

(b)

Figure 8 - Detailed view of (a) the Palmeiras Distrct in Beira; (b) Dondo village. Images obtained from Google.

The PCA method allows identifying land cover changes based on Remote Sensing images (Jensen, 1987). This technique consists of a spectral rotation of the original bands. The result is a set of new bands that have a minimum correlation. One of the properties of the principal components is that they summarize the common information of the input set. This property can be used to reduce the bands to be analyzed. For example, in our study, the four first main components explain $99 \%$ of the original variance. The first component summarizes the common information and often resembles a sum of all the bands. The second component, that still has a large amount of information, can store some properties that differentiate the land cover classes in the scene. However, components three and four stored information about land cover changes. The third component provided information about the contrast between the red band and the sum of the green and near-infrared bands. The forth component is very interesting. It can be seen as the difference of two the contrast between the near infrared and the visible in the two dates. This can be interpreted as the difference of two vegetation indexes. These two new bands became very useful to visualize the main changes caused by the cyclone. They allowed to also identify flooded areas produced by the passage of cyclone IDAI. These areas can be observed in figures 5, 6 and 7

\section{CONCLUSION}

Both methods are useful for detecting land changes between two dates. Using PCA will allow to identify land changes in through the transformation of the components obtained by improving the spectral differences between materials and surfaces. On the other hand, NDVI allows the detection of changes for two dates by means of the bands (near infrared and red), resulting in binary images corresponding to 1 (areas with vegetation) and 0 (other areas), respectively.

The results with respect to visual interpretation from the NDVI and PC images shows that due to cyclone Idai the green is decreased.

The change detection maps obtained from three methods show that areas of larger changes are identified in vegetated areas. The changes include the decrease of vegetated surfaces, built-up areas and increase of wet area. comparing PCA and NDVI methods, it was found that both are showing some common regions with high changes near vegetated areas and water bodies. By visual comparison, we found that the PCA stack vector approach outperforms the NDVI index-based methods. This paper aims to rapid access change detection in satellite images for flood disaster observation, so, to accurately map changes other methods and data (such as baseline water map, reference data of thematic map, land use land cover maps) should be integrated to generate the ground truth for pre-disaster and post-disaster images.

\section{ACKNOWLEDGEMENTS}

The authors would like to gratefully acknowledge funding from the Coordenação de Aperfeiçoamento de Pessoal de Nível Superior (CAPES) and Conselho Nacional de Desenvolvimento Científico e Tecnológico (CNPq) foundations.

\section{REFERENCES}

Consultec. (2007). Estudo Ambiental Simplificadoda Dragagem do Canal de Acesso ao Porto da Beira. Direcção de Engenharia dos Portos e Caminhos de Ferro de Moçambique EP, Beira.

Hussain, M., Chen, D., Cheng, A., Wei, H., Stanley, D., 2013. Change detection from remotely sensed images: From pixelbased to object-based approaches. ISPRS Journal of photogrammetry and remote sensing, 80, 91-106.

Jensen, J. R., Lulla, K., 1987. Introductory digital image processing: a remote sensing perspective.

Lu, D., Mausel, P., Brondizio, E., Moran, E., 2004. Change detection techniques. International journal of remote sensing, 25(12), 2365-2401.

Nzualo, T. N. M.; (2010). Estudo Hidrodinâmico e Ambiental do Estuário da Beira - Moçambique. Rio de Janeiro: Universidade Federal do Rio De Janeiro.

Otsu, N., 1979. A threshold selection method from gray-level histograms. IEEE transactions on systems, man, and Cybernetics, 9(1), 62-66.

Rouse, J. W.; Haas, R.H., Schell, J.A., Deering, D.W., 1973. Monitoring vegetation systems in the great plains with ERTS. Washington: NASA, v.1, p.309-317.

Tomowski, D., Ehlers, M., Klonus, S., 2011. Colour and texture-based change detection for urban disaster analysis. In 2011 Joint Urban Remote Sensing Event (pp. 329-332). IEEE.

Wickware, G. M., Howarth, P. J., 1981. Change detection in the Peace-Athabasca delta using digital Landsat data. Remote Sensing of Environment, 11, 9-25. 